\title{
ANALISA TINGKAT KESEHATAN KEUANGAN PT. BANK PERKREDITAN RAKYAT (BPR) BATANG PALANGKI
}

\author{
Shintia Mustika, Doni Marlius \\ Akademi Keuangan dan Perbankan "Pembangunan" Padang \\ sintyamustika55@gmail.com
}

\begin{abstract}
Bank are financial institutions that play a role in supporting economic development in a region, where the activitiesof raising funds and channeling funds in the form of loans or lending is a from of money circulation to stabilize the economy. The purpose of this study was to conduct an analysis of the level of bank financial health of the PT. Bank Perkreditan Rakyat (BPR) Batang Palangki, for the years 2014-2018. Historical data is taken from bank financial reports that have been published. Analysis of bank financial soundness using the CAMEL method (Capital, Assets, Management, Earning, Liquidity). The results showed that the 2014-2018 PT. BPR Batang Palangki financial health level showed a healthy category, where the average value of the CAR ratio was $28,66 \%$, the KAP ratio was $1,15 \%$, the NPM ratio was $24,88 \%$, the $R O A$ ratio was $3,38 \%, B O P O$ ratio of $74,83 \%$, and $L D R$ ratio of $56,30 \%$. It is expected that in the in the future BPR Batang Palangki can continue to maintained according to the provisions that apply.
\end{abstract}

Keywords : Bank soundness, CAMEL (CAR, KAP, NPM, ROA, BOPO, and LDR)

\section{PENDAHULUAN}

Perkembangan dunia perbankan di Indonesia saat ini semakin kompetitif yang mana menuntut setiap perbankan untuk dapat mengelolah dan melaksanakan manajemen perbankan menjadi lebih profesional (Rahmayeli \& Marlius, 2015). Bank merupakan badan usaha yang tugas utamanya sebagai lembaga perentara keuangan (financial intermediaries), yang menyalurkan dana dari pihak yang berkelebihan dana kepada pihak yang membutuhkan dana atau kekurangan dana pada waktu yang ditentukan. Dengan fungsinya tersebut perbankan dapat mendorong kegiatan ekonomi menjadi lebih efektif. Langkah strategis yang dapat dilakukan adalah dengan cara memperbaiki kinerja bank, kinerja yang baik diharapkan mampu meraih kembali kepercayaan masyarakat terhadap bank itu sendiri atau sistem perbankan secara keseluruhan. Pada sisi lain kinerja bank dapat pula dijadikan sebagai tolak ukur kesehatan bank tersebut (Laksito \& Sutapa, 2010).

Kepercayaan nasabah yaitu hal yang sangat penting agar kegiatan operasional perbankan dapat berjalan dengan baik. Dan harus didukung dengan tindakan pengawasan (supervising) yang di lakukan oleh lembaga pengawas 
perbankan yaitu Bank Indonesia agar lembaga perbankan Indonesia tidak rentan terhadap berbagai guncangan ekonomi baik yang berasal dari dalam negeri maupun luar negeri. Demi menjaga kepercayaan para deposan dan stabilitas sistem pembayaran, bank-bank yang beroperasi perlu dinilai tingkat kesehatannya (Jacob, 2013). Penilaian tingkat kesehatan yaitu gambaran dari suatu kinerja bank yang dapat digunakan sebagai tolak ukur oleh pihak yang berkepentingan dalam mengevaluasi apakah pengelolaan bank sudah dikerjakan sesuai dengan prinsip operasional bank yang sehat dan hati-hati, termasuk dalam mengelola resikoresiko yang ada. Penilaian tingkat kesehatan juga dijadikan sebagai tolak ukur dalam menetapkan arah pembinaan dan pengembangan bank baik secara individual maupun industri (Laksito \& Sutapa, 2010).

Analisis laporan keuangan yaitu suatu bentuk yang dapat digunakan untuk menilai kinerja perusahaan dalam keadaan baik atau tidak. Untuk mengetahui kondisi tersebut dapat dilakukan dengan berbagai analisis dan salah satunya yaitu dengan analisis rasio (Tanor, Sabijono, \& Walandouw, 2015). Menurut (Arifin \& Marlius, 2016) menyatakan bahwa analisis rasio keuangan merupakan alat utama dalam analisis keuangan, karena analisis ini dapat digunakan untuk menjawab berbagai pernyataan tentang keadaan perusahaan. Alat analisis yang digunakan untuk menilai tingkat kesehatan bank adalah CAMEL RATING SYSTEM. CAMEL merupakan faktor yang menentukan tingkat kesehatan suatu bank (Bala, 2017).

Penilaian kesehatan sebuah bank dapat dilakukan dengan pendekatan kualitatif melalui penilaian CAMEL yang terdiri dari beberapa komponen yang berpengaruh pada kondisi dan perkembangan suatu bank, seperti permodalan (Capital), faktor kualitas aktiva (Assets), faktor manajemen (Management), faktor rentabilitas (Earning), dan faktor likuiditas (Liquiditas). Predikat penilaian terhadap kesehatan sebuah bank dinilai dengan empat kriteria tingkat kesehatan yaitu sehat, cukup sehat, kurang sehat, dan tidak sehat (Puspita Rama Nopiana \& Chasanah, 2018). Berdasarkan Surat Edaran Bank Indonesia No. 6/23/DPNP tanggal 31 Mei 2004, penilaian tingkat kesehatan bank merupakan penilaian kualitatif atas berbagai aspek yang berpengaruh terhadap kondisi atau kinerja suatu bank melalui penilaian aspek permodalan, kualitas aset, manajemen, rentabilitas, likuiditas, dan sensivitas terhadap resiko pasar. Penggolongan tingkat kesehatan bank dibagi dalam empat kategori yaitu : sehat, cukup sehat, kurang sehat, dan tidak sehat. Kesehatan BPR adalah suatu bentuk penilaian konsumen atau masyarakatterhadap tingkat perkembangan suatu bank yang mana nantinya menjadi pengaruh besar bagi masyarakat untuk bergabung pada bank tersebut. bank yang sehat dijadikan sebagai patokan oleh masyarakat bahwa bank tersebut mampu berkembang dan dapat bersaing, serta mampu bertahan pada masanya (Putri \& Marlius, 2018).

Keberadaan BPR dapat membantu usaha mikro kecil dan menengah, semakin berkembangnya kebutuhan masyarakat. Tugas BPR tidak hanya ditujukan bagi masyarakat pedesaan saja tetapi juga mencakup pemberian jasa perbankan bagi masyarakat golongan ekonomi lemah di daerah perkotaan (Handayani \& Marlius, 2017). BPR sebagai salah satu bentuk lembaga keuangan yang juga diwajibkan oleh BI untuk mengukur tingkat kesehatannya dengan 
metode CAMEL ini, sehingga BPR harus sangat memperhatikan setiap rasio dalam CAMEL ini untuk mempertahankan tingkat kesehatannya (Zahara, 2015).

PT. Bank Perkreditan Rakyat Batang Palangki terletak di Jl. Lintas Sumatera, Pasar Ternak Lama, Palangki, Kabupaten Sijunjung. BPR ini berperan memberikan kontribusi aktif bagi keberhasilan pelaksanaan pembangunan khususnya dibidang penyediaan modal bagi masyarakat. Salah satu indikator yang digunakan untuk menilai keberhasilan atau kegagalan BPR dalam mencapai tujuan tersebut adalah laporan kinerja keuangan perusahaan yang telah dicapai. Penilaian atau analisis kinerja keuangan suatu BPR sangat penting, begitu juga bagi semua jenis usaha yang bertujuan untuk mencapai laba, serta untuk peningkatan dan pengembangan PT. BPR Batang Palangki untuk masa yang akan datang.

Sebagai perusahaan perbankan PT. BPR Batang Palangki harus memperhatikan masalah kesehatan bank. Pengelolaan permodalan, keadaan keuangan dan juga manajemen harus dilakukan sebaik-baiknya agar tingkat kesehatan keuangan bank terpelihara dengan baik serta untuk peningkatan dan perkembangan PT. BPR Batang Palangki untuk masa yang akan datang. Data mengenai data keuangan PT. BPR Batang Palangki pada tahun 2014-2018, dapat dilihat pada tabel berikut ini :

\section{Tabel 1}

\section{Data Keuangan PT. BPR Batang Palangki}

Tahun 2014-2018

(Ribuan Rp.)

\begin{tabular}{|c|c|c|c|c|c|}
\hline Indikator & 2014 & 2015 & 2016 & 2017 & 2018 \\
\hline Modal & 1.764 .724 & 2.607 .623 & 2.911 .093 & 3.440 .332 & 3.831 .538 \\
\hline$A T M R$ & 8.331 .956 & $9.129 .779,6$ & $10.182 .370,4$ & $9.810 .274,4$ & 9.164 .833 \\
\hline $\begin{array}{l}\text { Laba } \\
\text { sebelum } \\
\text { pajak }\end{array}$ & 506.876 & 527.597 & 484.303 & 457.515 & 447.434 \\
\hline Total asset & 11.489 .194 & 14.458 .035 & 17.723 .352 & 15.084 .079 & 14.420 .854 \\
\hline $\begin{array}{l}\text { Kredit yang } \\
\text { diberikan }\end{array}$ & 7.339 .601 & 7.617 .821 & 8.235 .939 & 8.417 .427 & 7.793 .698 \\
\hline $\begin{array}{l}\text { Dana pihak } \\
\text { ketiga }\end{array}$ & 8.866 .032 & 11.706 .846 & 14.553 .872 & 11.365 .535 & 10.278 .325 \\
\hline$A P Y D$ & $135.316,75$ & $150.806,25$ & $161.864,25$ & $208.891,25$ & $166.355,5$ \\
\hline $\begin{array}{l}\text { Jumlah asset } \\
\text { produktif }\end{array}$ & 11.247 .031 & 14.084 .689 & 17.519 .596 & 14.863 .369 & 14.313 .988 \\
\hline
\end{tabular}

Sumber : Laporan Keuangan PT. BPR Batang Palangki

Tabel 1 Mengidentifikasi terjadi fluktuasi atau ketidak tepatan rasio, karna adanya peningkatan dan penurunan nilai keuangan, seperti modal , ATMR, laba sebelum pajak, total asset, kredit yang diberikan, dana pihak ketiga, APYD, dan jumlah asset produktif dari PT. BPR Batang Palangki.

Pada tahun 2017 modal BPR Batang Palangki adalah 3.440.332 dan tahun 2018 dengan nilai 3.831.538 artinya modal BPR Batang Palangki mengalami 
peningkatan sebesar 391.206. Untuk ATMR pada tahun 2017 sebesar 9.810.274,4 dan ditahun 2018 sebesar 9.164.833 , berarti ATMR dari tahun 2017 ke tahun 2018 terjadi penurunan sebesar $645.441,4$. Untuk laba sebelum pajak dari tahun 2017 ke tahun 2018 terjadi penurunan sebesar 10.081 .

Untuk total aktiva dari tahun 2017 ke tahun 2018 mengalami penurunan sebesar 663.225. Untuk kredit yang diberikan dari tahun 2017 ke tahun 2018 mengalami penurunan sebanyak 623.729. Sedangkan untuk APYD dari tahun 2017 ke tahun 2018 mengalami penurunan sebesar 42.535,75, dan pada jumlah asset produktif dari tahun 2017 ke tahun 2018 juga mengalami penurunan sebesar 549.381.

Dari data di atas dapat disimpulkan bahwa hanya modal mengalami peningkatan, ATMR, laba sebelum pajak, total asset, kredit yang diberikan, dana pihak ketiga, APYD dan jumlah asset produktif mengalami penurunan. Melihat data diatas, maka sangat penting untuk menganalisis tingkat keuangan bank tersebut, sehingga dapat mempertahan operasional bank dalam menghadapi persaingan. Oleh karena itu diperlukan metode CAMEL yaitu Capital (Permodalan), Asset Quality (Kualitas Asset), Management (Manajemen), Earning (Rentabilitas), dan Liquidity (Likuiditas).

Berdasarkan uraian tersebut maka penulis tertarik untuk menganalisis dan menuangkan dalam bentuk tugas akhir yang berjudul "Analisis Tingkat Kesehatan Keuangan PT. Bank Perkreditan Batang Palangki”.

Berdasarkan uraian latar belakang diatas, maka rumusan masalah dalam penelitian ini adalah "Bagaimana tingkat kesehatan keuangan PT. Bank Perkreditan Rakyat batang Palangki?". Penelitian ini bertujuan untuk mengetahui tingkat kesehatan PT. BPR Batang Palangki selama periode tahun 2014-2018 dengan metode CAMEL.

Adapun manfaat penelitian ini, Penulis berharap penelitian ini dapat bermanfaat baik bagi penulis, perusahaan maupun perguruan tinggi, manfaatnya yaitu : a. Bagi Penulis, penelitian ini dapat meningkatkan wawasan dan memperluas pengetahuan tentang tingkat kesehatan keuangan PT. BPR Batang Palangki dengan menggunakan metode CAMEL. b. Bagi Perusahaan, sebagai tolak ukur bagi manajemen PT. BPR Batang Palangki untuk menilai apakah pengelolaan bank sudah dilaksanakan sesuai dengan peraturan yang telah ditetapkan dan sebagai acuan atau masukan utuk menentukan strategi usaha dan kebijakan dimasa yang akan datang. c. Bagi Akademi, diharapkan hasil penelitian ini khususnya dibidang keuangan dan perbankan dapat menambah referensi, informasi dan wawasan untuk penelitian lebih lanjut atau sebagai bahan kepustakaan serta sumber pengetahuan.

\section{METODE PENELITIAN}

Dalam pengumpulan data dan bahan untuk penelitian ini digunakan metode penelitian sebagai berikut : a. Metode Pengumpulan Data yaitu, 1) Rised Lapangan (Field Research), peninjauan langsung ke objek penelitian yang dipilih untuk meneliti hasil data primer. Penelitian langsung ke lapangan ini akan dapat membantu penulis untuk melengkapi data yang diperlukan. Adapun cara riset lapangan ini adalah dengan mewawancarai langsung pihak-pihak yang 
berkepentingan dalam hal ini adalah PT. BPR Batang Palangki. 2) Riset Perpustakaan (Librery Research), penelitian yang dilakukan melalui kepustakaan ataupun buku-buku, makalah-makalah, artikel-artikel, bacaan laporan-laporan dan publikasi yang ada hubungannya dengan pembahasan yang dilakukan. Penelitian perpustakaan ini bersifat teoritis, dimana dapat diaplikasikan dengan teori-teori yang berhubungan denganpenulisan ini. b. Metode Analisa Data, dalam analisa data, penulis menggunakan analisa data kuantitatif. Data kuantitatif merupakan data informasi yang berbentuk data yang dinyatakan dalam bentuk angka hasil dari perhitungan dan pengukuran. Maka dengan metode ini penulis akan mencoba memberikan fakta-fakta atau kenyataan yang dialami dengan teori-teori yang ada. Dimana metode kualitatif menggambarkan, memahami dan menjelaskan data yang diteliti selama penelitian berlangsung, sedangkan metode kuantitatif menganalisa perhitungan dari analisis laporan keuangan di suatu bank. Analisis ini digunakan untuk mengetahui analisa tingkat kesehatan keuangan bank yang kurang sehat atau sehat.

\section{ANALISIS}

\section{Permodalan (Capital)}

Keberhasilan suatu bank bukan hanya terletak pada jumlah modal yang dimilikinya melainkan berdasarkan kepada bagaimana bank tersebut menggunakan modalnya untuk menarik sebanyak mungkin dana simpanan masyarakat yang kemudian nantinya akan disalurkan kembali kepada masyarakat yang membutuhkannya sehingga membentuk pendapatan bagi bank tersebut (Jacob, 2013).

Rasio ini digunakan untuk mengukur sejauh mana penurunan yang terjadi dalam total aktiva yang bisa ditutupi oleh modal yang tersedia. Penilaian terhadap permodalan PT. BPR Batang Palangki menggunakan rasio CAR yang merupakan perbandingan antar modal dengan aktiva tertimbang menurut resiko, dapat diketahui pada tabel dibawah ini :

\section{Tabel 2}

CAR PT. BPR Batang Palangki

Tahun 2014-2018

\begin{tabular}{|c|c|c|c|c|c|c|c|c|c|c|}
\hline \multirow[b]{2}{*}{ KeterangaI } & \multicolumn{2}{|c|}{2014} & \multicolumn{2}{|c|}{2015} & \multicolumn{2}{|c|}{2016} & \multicolumn{2}{|c|}{2017} & \multicolumn{2}{|c|}{2018} \\
\hline & $\begin{array}{c}\text { Jumlah I } \\
\text { (Ribuan } \\
\text { Rp.) } \\
\end{array}$ & $\begin{array}{c}\text { Peningka } \\
\text { an } \\
(\%)\end{array}$ & $\begin{array}{c}\text { Jumlah } \\
\text { (Ribuan Rp. }\end{array}$ & $\begin{array}{c}\text { Peningka } \\
\text { an } \\
(\%)\end{array}$ & $\begin{array}{c}\text { Jumlah } \\
\text { (Ribuan } \\
\text { Rp.) } \\
\end{array}$ & $\begin{array}{c}\text { Peningka } \\
\text { an } \\
(\%)\end{array}$ & $\begin{array}{c}\text { Jumlah } \\
\text { (Ribuan Rp. }\end{array}$ & $\begin{array}{l}\begin{array}{l}\text { Peningl } \\
\text { atan } \\
(\%)\end{array} \\
\end{array}$ & $\begin{array}{c}\text { Jumlah } \\
\text { (Ribual } \\
\text { Rp.) } \\
\end{array}$ & $\begin{array}{l}\text { Peningl } \\
\text { atan } \\
(\%) \\
\end{array}$ \\
\hline $\begin{array}{c}\text { a. } \\
\text { Jumlah } \\
\text { modal }\end{array}$ & $\begin{array}{c}1.764 .7 \\
24\end{array}$ & - & 1.522 .240 & $\begin{array}{c}86,26 \\
\%\end{array}$ & $\begin{array}{c}2.911 .09 \\
3\end{array}$ & $\begin{array}{c}91,24 \\
\%\end{array}$ & 3.440 .332 & $\begin{array}{c}18,1 \\
8 \%\end{array}$ & $\begin{array}{c}3.831 . \\
538\end{array}$ & $\begin{array}{l}11,3 \\
7 \%\end{array}$ \\
\hline $\begin{array}{c}\text { b. } \\
\text { Jumlah } \\
\text { ATMR }\end{array}$ & $\begin{array}{c}8.331 .9 \\
56\end{array}$ & - & $\begin{array}{c}9.129 .779 \\
6\end{array}$ & $9,58 \%$ & $\begin{array}{c}10.182 .3 \\
70,4\end{array}$ & $\begin{array}{c}11,53 \\
\%\end{array}$ & $\begin{array}{c}9.810 .274 \\
4\end{array}$ & $\begin{array}{c}96,3 \\
5 \%\end{array}$ & $\begin{array}{c}9.164 . \\
833\end{array}$ & $\begin{array}{c}93,4 \\
2 \%\end{array}$ \\
\hline $\begin{array}{c}\mathrm{CAR}= \\
\mathrm{a} / \mathrm{b} \times 100 \\
\%\end{array}$ & 21,18 & & 16,67 & & 28,5 & $9 \%$ & $35,07 \%$ & & 41,8 & \\
\hline
\end{tabular}

Sumber : Data Olahan 
Perhitungan Nilai Kredit (NK) CAR

$$
\begin{aligned}
& N K=\frac{\text { Rasio }}{0,1 \%}+1 \\
& N K 2014=\frac{21,18 \%}{0,1 \%}+1=212,8 \% \\
& N K 2015=\frac{16,67 \%}{0,01 \%}+1=167,7 \% \\
& N K 2016=\frac{28,59 \%}{0,1 \%}+1=286,9 \% \\
& N K 2017=\frac{35,07 \%}{0,1 \%}+1=351,7 \% \\
& N K 2018=\frac{41,81 \%}{0,1 \%}+1=419,1 \%
\end{aligned}
$$

2. Kualitas Aktiva Produktif (Asset Quality)

Penilaian KAP yang dimiliki dapat diukur dengan 2 cara yaitu :

a. Rasio KAP/APYD terhadap Aktiva Produktif

Rasio KAP?APYD terhadap Aktiva Produktif merupakan penjumlahan aktiva produktif yang tergolong tidak lancar setelah dikalikan bobotnya. Rasio ini digunakan untuk mengukur tingkat kemungkinan diterimanya kembali dana yang ditanamkan. Semakin kecil rasio KAP, maka semakin besar tingkat kemungkinan diterimanya kembali dana yang ditanamkan. APYD menggambarkan Aktiva Produktif yang kurang lancar, diragukan, atau macet.

Tabel 3

\section{Laporan Kolektibilitas Aktiva Produktif PT. BPR Batang Palangki}

Tahun 2014-2018

(Ribua

n Rp.)

\begin{tabular}{cccccc}
\hline \multirow{2}{*}{ Komponen } & \multicolumn{5}{c}{ Tahun } \\
\cline { 2 - 6 } & $\mathbf{2 0 1 4}$ & $\mathbf{2 0 1 5}$ & $\mathbf{2 0 1 6}$ & $\mathbf{2 0 1 7}$ & $\mathbf{2 0 1 8}$ \\
\hline Jumlah APYD & $135.316,75$ & $150.806,25$ & $161.864,25$ & $208.891,25$ & $166.355,75$ \\
Jumlah Aktiva & 11.247 .031 & 14.084 .689 & 17.519 .596 & 14.863 .369 & 14.313 .988 \\
\hline Produktif & & & &
\end{tabular}

Sumber : Data diolah

Perhitungan Rasio KAP PT. BPR Batang Palangki adalah sebagai berikut :

$$
\begin{gathered}
K A P=\frac{\text { Jumlah Aktiva Produktif Yang Diklasifikasikan }}{\text { Jumlah Aktiva Produktif }} \times 100 \% \\
K A P 2014=\frac{135.316,75}{11.247 .031} \times 100 \%=1,20 \% \\
K A P 2015=\frac{150.806,25}{14.084 .689} \times 100 \%=1,07 \% \\
K A P 2016=\frac{161.864,25}{17.519 .596} \times 100 \%=0,92 \%
\end{gathered}
$$




$$
\begin{aligned}
& K A P 2017=\frac{208.891,25}{14.863 .369} \times 100 \%=1,41 \% \\
& K A P 2018=\frac{166.355,5}{14.313 .988} \times 100 \%=1,16 \% \\
& \text { Perhitungan Nilai Kredit (NK) Rasio KAP : }
\end{aligned}
$$

$N K 2014=\frac{22,5 \%-1,20 \%}{0,15 \%}=148($ maksimum 100$)$

$N K 2015=\frac{22,5 \%-1,07 \%}{0,15 \%}=148($ maksimum 100$)$

NK $2016=\frac{22,5 \%-0,92 \%}{0,15 \%}=149($ maksimum 100$)$

$N K 2017=\frac{22,5 \%-1,41 \%}{0,15 \%}=148($ maksimum 100$)$

NK $2018=\frac{22,5 \%-1,16 \%}{0,15 \%}=148($ maksimum 100$)$

b. Rasio PPAP

PPAP yaitu penyisihan penghapusan Aktiva Produktif yang dibentuk guna menutup resiko kemungkinan kerugian. Semakin besar PPAP, maka modal bank akan semakin kecil karena besarnya PPAP ini dicadangkan dari modal. Berikut hasil perhitungan rasio PPAP PT. BPR Batang Palangki tahun 2014-2018.

Tabel 4

\section{Laporan Kolektibilitas Aktiva Produktif \\ PT. BPR Batang Palangki \\ Tahun 2014-2018}

\begin{tabular}{cccccc} 
& & \multicolumn{3}{c}{ (Ribuan Rp.) } \\
\hline \multirow{2}{*}{ Komponen } & \multicolumn{3}{c}{ Tahun } & $\mathbf{2 0 1 7}$ & $\mathbf{2 0 1 8}$ \\
\cline { 2 - 6 } & $\mathbf{2 0 1 4}$ & $\mathbf{2 0 1 5}$ & $\mathbf{2 0 1 6}$ & $\mathbf{2 0 1 7}$ \\
\hline PPAP & 0 & 94.730 & 85.714 & 84.597 & 83.230 \\
PPAPWD & $151.494,12$ & $205.227,37$ & $235.968,275$ & $237.994,715$ & $214.379,645$ \\
\hline
\end{tabular}

Sumber : Data olahan

$$
\begin{aligned}
& \text { Perhitungan Rasio PPAP : } \\
& \text { Rasio PPAP }=\frac{P P A P}{P P A P W D} \times 100 \% \\
& \text { PPAP 2014 }=\frac{0}{151.494,12} \times 100 \%=0 \% \\
& \text { PPAP 2015 }=\frac{94.730}{205.227,37} \times 100 \%=4,61 \% \\
& \text { PPAP 2016 }=\frac{85.714}{235.968,275} \times 100 \%=3,63 \% \\
& \text { PPAP 2017 }=\frac{84.597}{237.994,715} \times 100 \%=3,55 \% \\
& P P A P 2018=\frac{83.230}{214.379,645} \times 100 \%=3,88 \%
\end{aligned}
$$


Perhitungan Nilai Kredit (NK) PPAP :

$$
\begin{aligned}
& N K 2014=\frac{0 \%}{1 \%}=0 \\
& N K 2015=\frac{4,61 \%}{1 \%}=4,61 \\
& N K 2016=\frac{3,63 \%}{1 \%}=3,63 \\
& N K 2017=\frac{3,55 \%}{1 \%}=3,55 \\
& N K 2018=\frac{3,88 \%}{1 \%}=3,88
\end{aligned}
$$

3. Manajemen (Management)

Aspek manajemen dapat diproyeksikan dengan pengukuran rasio yang menggambarkan tingkat keuntungan (laba) secara keseluruhan yang diperoleh bank dibandingkan dengan pendapatan yang diterima dari kegiatan operasionalnya. Penilaian aspek manajemen dapat dilakukan dengan menggunakan perhitungan rasio NPM. Perhitungannya dapat dilihat dari tabel berikut ini :

Tabel 5

Perhitungan Faktor Manajemen

PT. BPR Batang Palangki

Tahun 2014-2018

(Ribuan Rp.)

\begin{tabular}{llllll}
\hline \multirow{2}{*}{ Komponen } & \multicolumn{5}{c}{ Tahun } \\
\cline { 2 - 6 } & \multicolumn{1}{c}{$\mathbf{2 0 1 4}$} & \multicolumn{1}{c}{$\mathbf{2 0 1 5}$} & $\mathbf{2 0 1 6}$ & $\mathbf{2 0 1 7}$ & \multicolumn{2}{c}{$\mathbf{2 0 1 8}$} \\
\hline Laba Bersih & 486.779 & 503.999 & 457.890 & 431.418 & 429.052 \\
Pendapatan & 1.616 .551 & 1.775 .842 & 2.016 .018 & 1.996 .125 & 1.985 .126 \\
Operasional & & & & & \\
\hline
\end{tabular}

Sumber : Laporan Keuangan PT. BPR Batang Palangki

Perhitungan rasio NPM sebagai berikut :

$$
\begin{aligned}
& N P M=\frac{\text { Laba Bersih }}{\text { Pendapatan Operasional }} \times 100 \% \\
& N P M 2014=\frac{486.779}{1.616 .551} \times 100 \%=30,11 \% \\
& N P M 2015=\frac{503.999}{1.775 .842} \times 100 \%=28,38 \% \\
& N P M 2016=\frac{457.890}{2.016 .018} \times 100 \%=22,71 \% \\
& N P M 2017=\frac{431.418}{1.996 .125} \times 100 \%=21,61 \% \\
& N P M 2018=\frac{429.052}{1.985 .126} \times 100 \%=21,61 \%
\end{aligned}
$$


4. Rentabilitas (Earning)

Dalam penghitungan rentabilitas digunakan dua rasio yaitu Return On Asset (ROA) dan rasio Biaya Operasional terhadap Pendapatan Operasional (BOPO). ROA adalah perbandingan laba sebelum pajak dengan rata-rata total aktiva, sementara BOPO adalah perbandingan pendapatan operasional.

\section{Tabel 6 \\ Perhitungan Faktor Rentabilitas \\ PT. BPR Batang Palangki \\ Tahun 2014-2018}

(Ribua

n Rp.)

\begin{tabular}{cccccc}
\hline \multirow{2}{*}{ Komponen } & \multicolumn{5}{c}{ Tahun } \\
\cline { 2 - 5 } & $\mathbf{2 0 1 4}$ & $\mathbf{2 0 1 5}$ & $\mathbf{2 0 1 6}$ & $\mathbf{2 0 1 7}$ & $\mathbf{2 0 1 8}$ \\
\hline Laba Sebelum Pajak & 506.876 & 527.597 & 484.303 & 457.515 & 447.434 \\
Total Aktiva & 11.489 .194 & 14.458 .035 & 17.723 .352 & 15.084 .079 & 14.420 .854 \\
Beban Operasional & 1.123 .401 & 1.248 .245 & 1.609 .215 & 1.538 .960 & 1.537 .692 \\
Pendapatan & 1.616 .551 & 1.775 .842 & 2.016 .018 & 1.996 .125 & 1.985 .126 \\
Operasional & &
\end{tabular}

Sumber : Laporan Keuangan PT. BPR Batang Palangki

1. Perhitungan Rasio ROA

$$
\begin{aligned}
& R O A=\frac{\text { Laba Sebelum Pajak }}{\text { Total Aktiva }} \times 100 \% \\
& \text { ROA } 2014=\frac{506.876}{11.489 .194} \times 100 \%=4,41 \% \\
& \text { ROA } 2015=\frac{527.597}{14.458 .035} \times 100 \%=3,65 \% \\
& \text { ROA } 2016=\frac{484.303}{17.723 .352} \times 100 \%=2,73 \% \\
& \text { ROA } 2017=\frac{457.515}{15.084 .079} \times 100 \%=3,03 \% \\
& \text { ROA } 2018=\frac{447.434}{14.420 .854} \times 100 \%=3,10 \%
\end{aligned}
$$

Perhitungan Nilai Kredit (NK) ROA :

$N K 2014=\frac{4,41 \%}{0,015 \%}=294($ maksimum 100$)$

NK $2015=\frac{3,65 \%}{0,015 \%}=243($ maksimum 100$)$

$N K 2016=\frac{2,73 \%}{0,015 \%}=182($ maksimum 100$)$

NK $2017=\frac{3,03 \%}{0,015 \%}=202($ maksimum 100$)$

NK $2018=\frac{3,10 \%}{0,015 \%}=207$ (maksimum 100) 
2. Perhitungan Rasio BOPO

$$
\begin{aligned}
& \text { ВОРО }=\frac{\text { Beban Operasional }}{\text { Pendapatan Operasional }} \times 100 \% \\
& \text { ВОРО } 2014=\frac{1.123 .410}{1.616 .551} \times 100 \%=69,49 \% \\
& \text { ВОРО } 2015=\frac{1.248 .245}{1.775 .842} \times 100 \%=70,29 \% \\
& \text { ВОРО } 2016=\frac{1.609 .215}{2.016 .018} \times 100 \%=79,82 \% \\
& \text { ВОРО } 2017=\frac{1.538 .960}{1.996 .125} \times 100 \%=77,10 \% \\
& \text { ВОРО } 2018=\frac{1.537 .692}{1.985 .126} \times 100 \%=77,46 \%
\end{aligned}
$$

Perhitungan Nilai Kredit (NK) BOPO

5. Likuiditas (Liquidity)

$$
\begin{aligned}
& \text { NK } 2014=\frac{100 \%-69,49 \%}{0,08 \%}=381(\text { maksimum } 100) \\
& N K 2015=\frac{100 \%-70,29 \%}{0,08 \%}=371(\text { maksimum } 100) \\
& N K 2016=\frac{100 \%-79,82 \%}{0,08 \%}=252(\text { maksimum } 100) \\
& N K 2017=\frac{100 \%-77,10 \%}{0,08 \%}=286(\text { maksimum } 100) \\
& N K 2018=\frac{100 \%-77,46 \%}{0,08 \%}=282(\text { maksimum } 100)
\end{aligned}
$$

Likuiditas yaitu kemampuan untuk memenuhi kewajiban finansial jangka pendek tepat pada waktu yang ditunjukkan oleh besar kecilnya aktiva lancar. Penilaian likuiditas dimaksudkan untuk mengevaluasi kemampuan bank dalam menjaga tingkat likuiditas yang memadai dan kecakupan manajemen resiko likuiditas.

Tabel 7

Perhitungan Faktor Likuiditas

PT. BPR Batang Palangki

Tahun 2014-2018

(Ribuan Rp.)

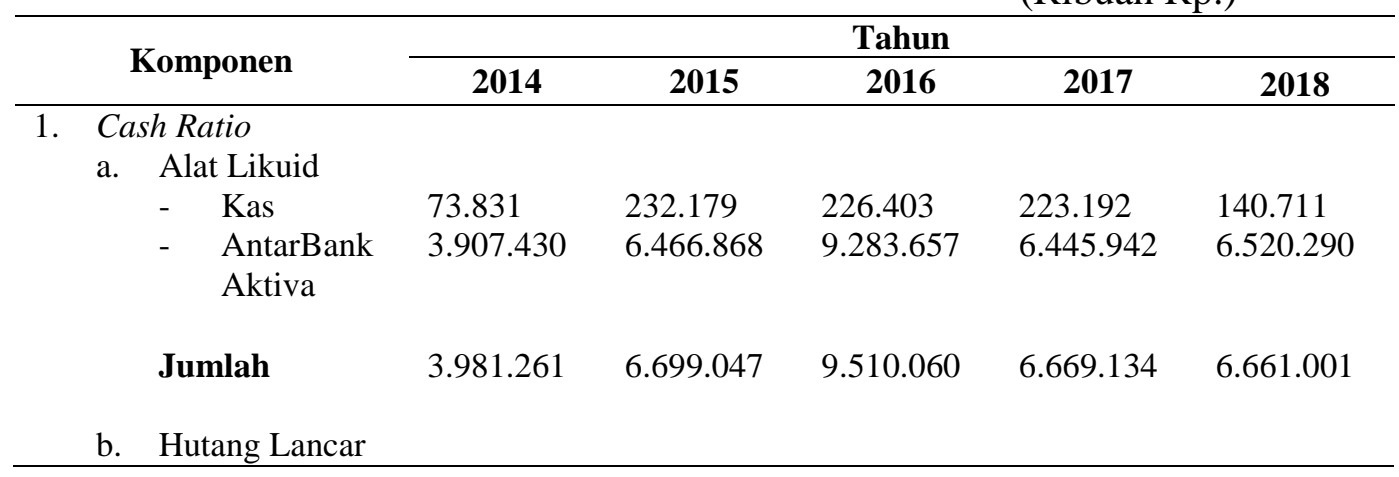




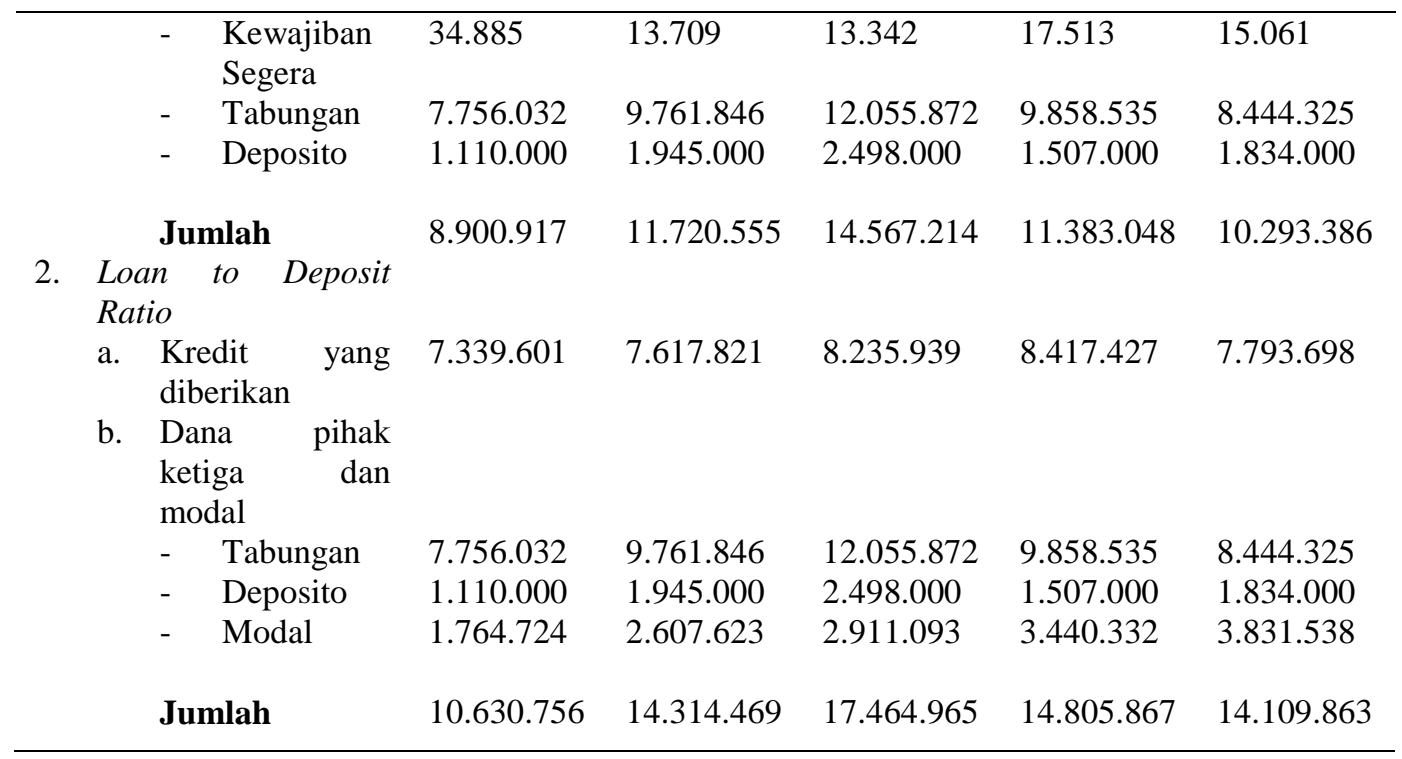

Sumber : Data diolah

Perhitungan CR

$C R=\frac{\text { Alat Likuid }}{\text { Hutang Lancar }} \times 100 \%$

$C R 2014=\frac{3.981 .261}{8.900 .917} \times 100 \%=44,73 \%$

CR $2015=\frac{6.699 .047}{11.720 .555} \times 100 \%=57,16 \%$

$C R 2016=\frac{9.510 .060}{14.567 .214} \times 100 \%=65,28 \%$

CR $2017=\frac{6.669 .134}{11.383 .048} \times 100 \%=58,59 \%$

CR $2018=\frac{6.661 .001}{10.293 .386} x 100 \%=64,71 \%$

Perhitungan Nilai Kredit (NK) CR

$N K=\frac{\text { Angka Rasio }}{0,05 \%} x 1$

$N K 2014=\frac{44,73 \%}{0,05 \%} x 1=894,6$

$N K 2015=\frac{57,16 \%}{0,05 \%} x 1=1.143,2$

$N K 2016=\frac{65,28}{0,05 \%} x 1=1.305,6$

$N K 2017=\frac{58,59 \%}{0,05 \%} x 1=1.171,8$

$N K 2018=\frac{64,71 \%}{0,05 \%} x 1=1.294$ 
Perhitungan Rasio LDR

$$
\begin{aligned}
& L D R=\frac{\text { Kredit yang diberikan }}{\text { Dana pihak ketiga }+ \text { modal }} \times 100 \% \\
& \text { LDR } 2014=\frac{7.339 .601}{10.630 .756} \times 100 \%=69,04 \% \\
& \text { LDR } 2015=\frac{7.617 .821}{14.314 .469} \times 100 \%=53,22 \% \\
& \text { LDR } 2016=\frac{8.235 .939}{17.464 .965} \times 100 \%=47,16 \% \\
& \text { LDR } 2017=\frac{8.417 .427}{14.805 .867} \times 100 \%=56,85 \% \\
& \text { LDR } 2018=\frac{7.793 .698}{14.109 .863} \times 100 \%=55,24 \% \\
& \text { Perhitungan Nilai Kredit (NK) LDR : } \\
& N K=\frac{115 \%-\text { Angka Rasio }}{1 \%} \times 4 \\
& N K 2014=\frac{115 \%-69,04 \%}{1 \%} x 4=183,84(\text { maksimum } 100) \\
& \text { NK } 2015=\frac{115 \%-53,22 \%}{1 \%} x 4=247,12(\text { maksimum } 100) \\
& \text { NK } 2016=\frac{115 \%-47,16 \%}{1 \%} x 4=271,36(\text { maksimum } 100) \\
& \text { NK } 2017=\frac{115 \%-56,85 \%}{1 \%} \times 4=232,6(\text { maksimum } 100) \\
& N K 2018=\frac{115 \%-55,24 \%}{1 \%} x 4=239,04(\text { maksimum } 100)
\end{aligned}
$$

\section{PEMBAHASAN}

1. Penilaian permodalan

\section{Tabel 8}

Nilai PK Komponen CAR

\begin{tabular}{ccc}
\hline Periode & CAR (\%) & Keterangan \\
\hline 2014 & 21,18 & Sehat \\
2015 & 16,67 & Sehat \\
2016 & 28,59 & Sehat \\
2017 & 35,07 & Sehat \\
2018 & 41,81 & Sehat \\
\hline
\end{tabular}

\section{Sumber : Data Olahan}

Berdasarkan tabel 8 dapat diketahui bahwa rasio CAR BPR Batang Palangki mendapatkan predikat sehat, karena BPR Batang Palangki memiliki CAR melebihi standar minimal BI yaitu sebesar $8 \%$. Hasil perhitungan pada tabel 3.8, nilai CAR BPR mengalami fluktuasi. CAR mengalami penurunan dari tahun 2014 sebesar 21,18\% pada tahun 2015 turun sebesar 16,67\%. Kembali naik pada tahun 2016 menjadi 28,59\%, dan pada tahun 2017 mengalami peningkatan menjadi 35,07\%. Kembali naik pada tahun 2018 menjadi 41,81\%, secara keseluruhan posisi CAR BPR Batang Palangki selalu berada di atas batas minimum CAR yang 
telah ditetapkan Bank Indonesia yaitu 8\%. Artinya dapat dikatakan BPR memiliki tingkat kecukupan modal yang baik atas pemenuhan kewajiban yang dimilikinya, baik dalam mendanai kegiatan operasionalnya ataupun untuk menghadapi resiko yang akan terjadi.

2. Penilaian Aktiva Produktif (Asset Quality)

a. Rasio KAP

Tabel 9

Nilai PK Komponen KAP

\begin{tabular}{ccc}
\hline Periode & KAP $(\%)$ & Keterangan \\
\hline 2014 & 1,20 & Sehat \\
2015 & 1,07 & Sehat \\
2016 & 0,92 & Sehat \\
2017 & 1,41 & Sehat \\
2018 & 1,16 & Sehat \\
\hline
\end{tabular}

Sumber : Data Olahan

Berdasarkan tabel 9, KAP BPR Batang Palangki pada tahun mengalami penurunan tahun 2014 sebesar 1,20\%, pada tahun 2015 dan 2016 turun menjadi 1,07\% dan 0,92\%. Mengalami peningkatan pada tahun 2017 menjadi 1,41\%, kembali turun pada tahun 2018 menjadi $1,16 \%$. Tetapi KAP BPR Batang Palangki dapat dikatakan masih dalam kategori penilaian sehat, karena masih dalam penggolongan penilaian yaitu $0,00 \%-\leq 10,35 \%$.

b. Rasio PPAP

\section{Tabel 10}

Nilai PK Komponen PPAP

\begin{tabular}{ccc}
\hline Periode & PPAP $(\boldsymbol{\%})$ & Ketegori \\
\hline 2014 & 0 & Tidak Sehat \\
2015 & 4,61 & Tidak Sehat \\
2016 & 3,63 & Tidak Sehat \\
2017 & 3,55 & Tidak Sehat \\
2018 & 3,88 & Tidak Sehat \\
\hline
\end{tabular}

Sumber : Data Olahan

Berdasarkan tabel 10, pada tahun 2014-2018 PPAP yang dimiliki PT. BPR batang Palangki termasuk kedalam kategori tidak sehat. Karena tingkat penilaian PPAP diatas $81 \%$ dinyatakan sehat dan dibawah atau kurang dari 50,99\% dinyatakan tidak sehat. Dapat di analisa bahwa aktiva produktif termasuk kedalam kategori kredit macet dan mengalami penurunan, karena tidak mampunya bank dalam menjaga pinjaman yang disalurkan dengan baik.

3. Penilaian Manajemen (Management)

Tabel 11

Nilai PK Komponen NPM

\begin{tabular}{ccc}
\hline Periode & NPM $(\boldsymbol{\%})$ & Kategori \\
\hline 2014 & 30,11 & Sehat \\
2015 & 28,38 & Sehat \\
2016 & 22,71 & Sehat \\
2017 & 21,61 & Sehat \\
2018 & 21,61 & Sehat \\
\hline
\end{tabular}

Sumber : Data Olahan 
Berdasarkan tabel 11, NPM dapat di katakan sehat yaitu besar dari 5\%. Nilai NPM pada tahun 2014 sebesar 30,11\%, kemudian mengalami penurunan pada tahun 2015, 2016, 2017 dan 2018 menjadi 28,38\%, $22,71 \%, 21,61 \%$ dan 21,61\%. Walaupun mengalami penurunan, tetapi NPM BPR Batang Palangki masih dalam kategori sehat. Bank dapat dikatakan baik dalam mengukur kemampuan pendapatan operasional untuk menghasilkan laba.

4. Penilaian Rentabilitas (Earning)

a. Rasio ROA

Tabel 12

Nilai PK Komponen ROA

\begin{tabular}{ccc}
\hline Periode & ROA $(\%)$ & Ketegori \\
\hline 2014 & 4,41 & Sehat \\
2015 & 3,65 & Sehat \\
2016 & 2,73 & Sehat \\
2017 & 3,03 & Sehat \\
2018 & 3,10 & Sehat \\
\hline
\end{tabular}

Sumber : Data Olahan

Berdasarkan tabel 12, pada tahun 2014-2018 BPR batang Palangki memiliki rasio ROA lebih dari $1,22 \%$ perolehan laba sangat tinggi yaitu sebesar $4,41 \%$ pada tahun 2014 , mengalami penurunan pada tahun 2015 menjadi 3,65\%. Dan turun kembali pada tahun 2016 menjadi 2,73\%, tahun 2017 dan 2018 mengalami peningkatan menjadi $3,03 \%$ dan 3,10\% dengan kategori sehat. Walaupun terjadi fluktuasi terhadap ROA BPR Batang Palangki, tetapi masih dalam keadaan sehat.

2. Rasio BOPO

Tabel 13

Nilai PK Komponen BOPO

\begin{tabular}{ccc}
\hline Periode & BOPO $(\%)$ & Kategori \\
\hline 2014 & 69,49 & Sehat \\
2015 & 70,29 & Sehat \\
2016 & 79,82 & Sehat \\
2017 & 77,10 & Sehat \\
2018 & 77,46 & Sehat \\
\hline
\end{tabular}

Sumber : Data Olahan

Berdasarkan tabel 13, rasio BOPO BPR Batang Palangki dalam kategori sehat karena berada di bawah 93,52\%. Pada tahun 2014 BOPO BPR Batang palangki sebesar 69,49\%, mengalami peningkatan pada tahun 2015, 2016, 2017 dan 2018 menjadi 70,29\%, $79,82 \%, 77,10 \%$ dan $77,46 \%$. 
5. Penilaian Likuiditas (Likuidity)

a. Rasio CR

Tabel 14

Nilai PK Komponen CR

\begin{tabular}{ccc}
\hline Periode & CR $(\boldsymbol{\%})$ & Kategori \\
\hline 2014 & 44,73 & Sehat \\
2015 & 57,16 & Sehat \\
2016 & 65,28 & Sehat \\
2017 & 58,59 & Sehat \\
2018 & 64,71 & Sehat \\
\hline
\end{tabular}

Sumber : Data Olahan

Berdasarkan tabel 14, nilai CR BPR Batang Palangki dalam kategori sehat. Karena berada diatas standar yang telah di tetapkan oleh BI, yaitu diatas 4,05\%. CR pada tahun 2014 sebesar 44,73\%, mengalami kenaikan pada tahun 2015 dan 2016 menjadi 57,16\% dan 65,28\%. Kemudian mengalami penurunan pada tahun 2017 menjadi 58,59\%, kembali naik pada tahun 2018 menjadi 64,71\%.

b. Rasio LDR

Tabel 15

Nilai PK Komponen LDR

\begin{tabular}{ccc}
\hline Periode & LDR $(\boldsymbol{\%})$ & Keterangan \\
\hline 2014 & 69,04 & Sehat \\
2015 & 53,22 & Sehat \\
2016 & 47,16 & Sehat \\
2017 & 56,85 & Sehat \\
2018 & 55,24 & Sehat
\end{tabular}

Sumber : Data Olahan

Berdasarkan data tabel 15, tingkat rasio likuiditas BPR Batang Palangki yang dihitung menggunakan rumus LDR mendapatkan peringkat pertama karena kurang dari 93,75\%. Pada tahun 2014 sebesar 69,04\%, mengalami penurunan pada tahun 2015 dan 2016 menjadi $53,22 \%$ dan $47,16 \%$. Kemudian mengalami peningkatan pada tahun 2017 menjadi 56,85\%, kembali turun pada tahun 2018 menjadi 55,24\%. LDR BPR batang Palangki mengalami fluktuasi namun masih dapat di golongkan pada penilaian sehat, karena kurang dari $93,75 \%$ atau dari penggolongan penilaian.

\section{SIMPULAN}

Berdasarkan hasil analisis pada bab sebelumnya bahwa penelitian yang berjudul "Analisis Tingkat Kesehatan Keuangan pada PT. Bank Perkreditan Rakyat (BPR) Batang palangki” dapat disimpulkan sebagai berikut :

a) Capital (Permodalan) yaitu hasil CAR pada PT. BPR Batang Palangki untuk periode 2014-2018 berada dalam kategori sehat. Rasio permodalan yang diperoleh PT. BPR Batang Palangki selama tahun 2014-2018 adalah sebesar $21,18 \%, 16,67 \%, 28,59 \%, 35,07 \%$, dan 41,81\%. Rasio rata-rata selama 5 (lima) tahun adalah 28,664\% artinya masih di atas ketentuan yang ditetapkan Bank Indonesia (BI) yaitu 8\%. 
b) Asset Quality (Kualitas Aktiva Produktif) yaitu KAP yang dimiliki PT. BPR Batang Palangki untuk periode 2014-2018 sebesar 1,20\%, 1,07\%, $0,92 \%, 1,41 \%$, dan $1,16 \%$. Rasio PPAP yang diperoleh PT. BPR Batang Palangki selama tahun 2014-2018 adalah sebesar 0\%, 4,61\%, 3,63\%, $3,55 \%$, dan 3,88\% dinyatakan Tidak Sehat, dengan hasil analisa yang menunjukkan bahwa dalam kurung waktu 5 tahun terakhir aktiva produktif yang termasuk dalam kategori kredit macet mengalami penurunan, karena tidak mampu menjaga pinjaman yang disalurkan dengan baik.

c) Management (Manajemen) yaitu nilai NPM yang dimiliki PT. BPR Batang Palangki digolongkan dalam kategori sehat, karena dapat mencapai labanya. Hal ini ditunjukkan dengan rasio yang dihasilkan yaitu sebesar $30,11 \%, 28,38 \%, 22,71 \%, 21,61 \%$, dan 21,61\%. Meskipun terjadi fluktuasi akan tetapi masih berada diatas standar yang ditetapkan oleh BI yaitu diatas $5 \%$.

d) Earning (Rentabilitas) yang didasarkan pada ROA dan PT. BPR Batang Palangki dikategorikan sehat karena mampu menjaga ROA dengan baik diatas $1,215 \%$. Sedangkan untuk rasio BOPO dalam 5 periode tersebut tergolong sehat, karena dapat memenuhi kriteria sebagai bank yang sehat dengan rasio kurang dari 93,52\%, dan PT. BPR Batang Palangki berhasil meningkatkan pendapatannya.

e) Liquidity (Likuiditas) yang didasarkan pada Cash Ratio (CR) dalam lima tahun terakhir tergolong sehat, hal ini ditunjukkan dengan rasio yang dihasilkan yaitu sebesar 44,73\%, 57,16\%, 65,28\%, 58,59\%, dan 64,71\%. Meskipun terjadi fluktuasi akan tetapi masih berada diatas standar yang ditetapkan yaitu 4,05\%. Sedangkan untuk Loan to Deposit Ratio (LDR) periode 2014-2018 berada dalam kategori sehat, karena rasio LDR berada dibawah $94,75 \%$.

\section{UCAPAN TERIMAKASIH}

Terimakasih penulis sampaikan kepada :

1. Kedua Orang Tua yang senantiasa memberikan dukungan baik secara moril maupun materil.

2. Direktur AKBP beserta prodi AKBP yang telah memberikan kesempatan kepada penulis untuk melakukan penelitian ini.

3. Dosen Pembimbing yang telah memberikan arahan dan bimbingan hingga tugas akhir ini bisa terelesaikan.

4. Direktur PT. BPR Batang Palangki yang telah mengizinkan penulis dalam memperoleh informasi beserta pengambilan data.

5. Semua Pihak yang telah memberikan dukungan dan bantuannya dalam penyelesaian tugas akhir ini

\section{DAFTAR PUSTAKA}

Arifin, I. Z., \& Marlius, D. (2016). Analisis Kinerja Keuangan PT. Pegadaian Cabang Ulak Karang, 1-10. Retrieved from https://doi.org/10.31227/osf.io/n2peu 
Bala, R. P. (2017). Analisis Penilaian Terhadap Kesehatan BPR dengan Menggunakan Faktor CAMEL Berdasarkan Peraturan Bank Indonesia. JURNAL RISET MANAJEMEN \& AKUNTANSI (RMA), 8(1), 1-18.

Handayani, M., \& Marlius, D. (2017). Analisis Tingkat Kesehatan PT. BPR Batang Kapas, 1-21. https://doi.org/10.31227/osf.io/bq48z

Jacob, J. K. D. (2013). Analisis Laporan Keuangan dengan Menggunakan Metode CAMELuntuk Menilai Tingkat Kesehatan Perbankan, 1(3), 691-700.

Laksito, H., \& Sutapa. (2010). Memprediksi Kesehatan Bank dengan Rasio CAMELS pada Bank Perkreditan Rakyat. Jurnal Keuangan Dan Perbankan, 14(1), 156-167.

Puspita Rama Nopiana, \& Chasanah, M. (2018). Analisis Tingkat Kesehatan Bank Perkreditan Rakyat (BPR) Dengan Metode CAMEL di Kota Batam, 6(2), 34-43.

Putri, Y. A., \& Marlius, D. (2018). Analisis Tingkat Kesehatan Bank Pada PT. Bank Perkreditan Rakyat (BPR) Jorong Kampung Tangah Pariaman Cabang Padang, 1-10. Retrieved from https://doi.org/10.31227/osf.io/r98pv

Rahmayeli, D. S., \& Marlius, D. (2015). Analissi Kinerja Keuangan pada PT. Bank Perkreditan Rakyat (BPR) Batang Kapas Pesisir Selatan, 1-7. https://doi.org/10.31227/osf.io/sz5db

Setiyono, W. P., \& Aini, M. N. (2014). Analisis Kinerja Keuangan Perbankan dengan Menggunakan Metode CAMEL (Studi Kasus pada PT. BPR Buduran Delta Purnama). Jurnal Bisnis, Manajemen \& Perbankan, 1(2), 175-196. https://doi.org/https://doi.org/10.21070/jbmp.v1i2.271

Tanor, M. O., Sabijono, H., \& Walandouw, S. K. (2015). Analisis Laporan Keuangan dalam Mengukur Kinerja Keuangan pada PT. Bank Artha Graha Internasional,tbk. Jurnal Riset Ekonomi, Manajemen, Bisnis Dan Akuntansi, 3(3), 639-649.

Zahara. (2015). Analisis Tingkat Kesehatan bank Perkreditan Rakyat (BPR) dengan Metode CAMEL (Studi Kasus pada Tiga BPR di Sumatera Barat). Journal Accounting and Management, 61-75. Retrieved from http://www.polinpdg.ac.id 